\title{
Elektrokardiyografi Sinyallerinin Gerçek Zamanlı Kaydı İçin Ardunio Eklentisi Tasarımı
}

\section{Design of Arduino Shield to Record Real-Time Electrocardiography Signals}

\author{
${ }^{*}, 1$ Yalcin Isler and ${ }^{2}$ Onur Doganay Cagatay \\ ${ }^{1}$ Izmir Katip Celebi University, Department of Biomedical Engineering, Cigli, Izmir, Turkey \\ ${ }^{2}$ Izmir Katip Celebi University, Department of Biomedical Technologies, Cigli, Izmir, Turkey
}

\begin{abstract}
Özet
$\mathrm{Bu}$ çalışmada elektrokardiyografi (EKG) sinyalleri elde eden bir Arduino eklentisi yapılmıştır. Bu eklenti, üzerindeki seçici entegreler yardımıyla kullanıcı tarafından belirlenen 16 farklı giriş kanalı bulunmaktadır. İlk olarak seçilen kanallardaki EKG sinyalleri enstrümantal yükselteçle yükseltilir. Daha sonra aktif alçak ve yüksek filtrelerden ve notch (çentik) filtresinden geçirilir. Yükseltilmiş ve filtrelerden geçirilmiş EKG sinyali Arduino yardımıyla ara yüz programına gerçek zamanlı aktarılır. Ara yüz programını kontrol eden kullanııı giriş kanallarını, EKG sinyalinin kazancını, aktif alçak ve yüksek filtrelerin kesim frekansını değiştirebilir.
\end{abstract}

Anahtar kelimeler: Arduino eklentisi, elektrokardiyografi, ara yüz programı, gömülü sistemler.

\begin{abstract}
In this work, an Arduino shield is designed to take the electrocardiography (ECG) signals This shield has 16 different channel that identified by the user with the help of the components on it. Firstly, the ECG signals that is selected, amplify by the instrumental amplifier. After that, the signal percolate by the active low pass and high pass filters and also a notch filter. The ECG signal that amplified and percolated is transferred to the user interface in real time with the aid of Arduino. The user that has user interface could change inputs channels, the gains of the ECG signal and the cut off frequency of the active low and high pass filters.
\end{abstract}

Key words: Arduino shield, electrocardiography, user interface, embedded systems.

\section{Giriş}

EKG sinyali, kalbin kan pompalamasını sağlayan kalp kaslarının elektriksel aktivitesi sonucunda ortaya çıkan ve vücuda takılan elektrotlar sayesinde algılanabilen biyolojik işaretlerdir. Elektrokardiyogram kalple ilgili çeşitli hastalıkların klinik teşhisi için kullanılır [1]. EKG sinyali, $\mathrm{P}, \mathrm{Q}, \mathrm{R}, \mathrm{S}, \mathrm{T}$ ve $\mathrm{U}$ harfleriyle sembolize edilen bölgelerden meydana gelir. Bu harflerin her biri kalp kasının kanı pompalaması için yaptığı hareketin her bir evresini simgeler [2]. Şekil 1'de EKG sinyalinin ifade ettiği aralıklar; 1 uyarının sinoatriyal çıkışı, 2 atriyal aktivasyon, 3 atriyo ventriküler iletim, 4 ventrikül aktivasyon zamanı, 5 ventriküllerin tam olarak depolarize olması, 6 ventriküler repolarizasyon olarak belirtilmiştir [3]. EKG sinyalindeki önemli dalga şekillerinin

*Corresponding author. Address: Faculty of Engineering and Architecture, Department of Biomedical Engineering, Izmir Katip Celebi University, Balatick Campus, 35620, Izmir TURKEY. E-mail address: islerya@yahoo.com, Web: http://www.islerya.com 
gelikleri ve aralıkların süreleri literatürde tanımlanmıştır (Tablo 1 ve 2). Bu değerler devre tasarımında önemli ön bilgilerdir.

EKG sinyallerini elde edebilmek için, vücudun değişik yerlerine yerleştirilen elektrotlar, kablolar aracılığı ile elektrokardiyografiye bağlanır [4]. Vücuttan alınan EKG sinyalinin genliği maksimum $1 \mathrm{mV}$ 'dur. EKG sinyalinin işlenebilir olması için genliğinin yükseltilerek, işlenilebilir seviyelere getirilmesi gerekmektedir [5]. EKG sinyalinin frekans aralığ $0.1 \mathrm{~Hz}-100 \mathrm{~Hz}$ arasındadır. Tasarlanan ölçüm cihazlarında, çevresel manyetik alan, toprak çevrimleri gibi bozucu etkenlerden dolayı sorunlarla karşılaşılabilir [6]. Bu bozucu etkileri giderebilmek için, sağ bacak sürücü devreleri, gürültü korumalı, ekranlı elektrot kabloları ve her giriş için eşit ortak mod giriş empedansı kullanılması gerekmektedir [7].

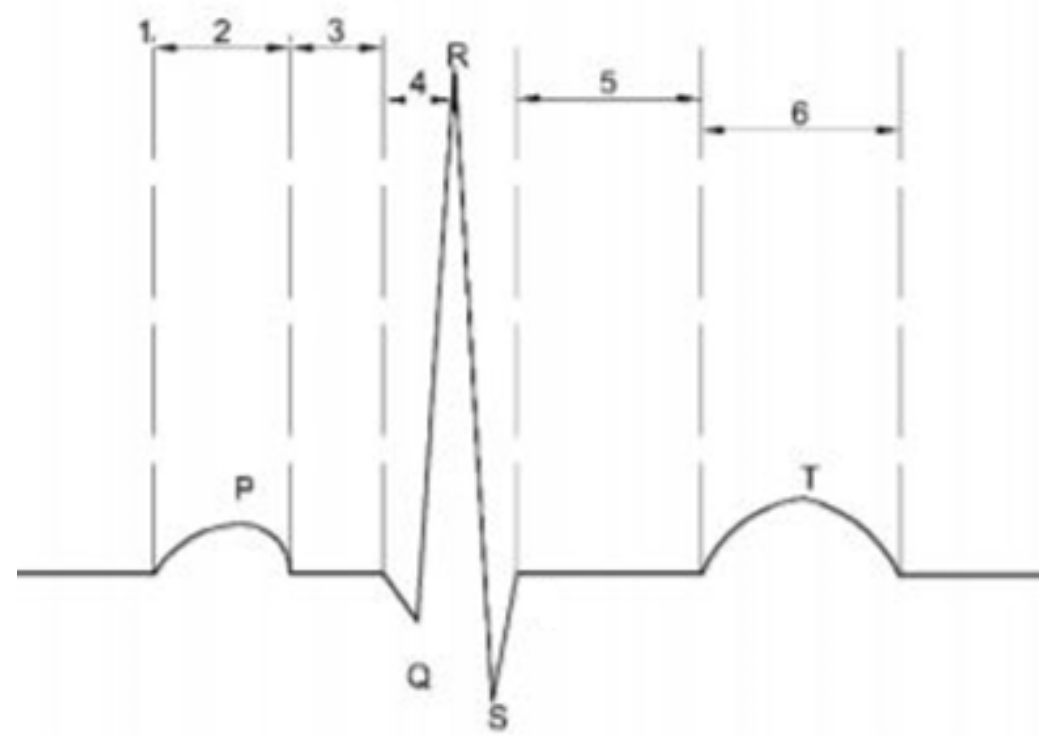

Şekil 1. EKG sinyali şekli üzerinde önemli dalgalar ve aralıkların isimlendirilmesi

Tablo 1. EKG sinyalindeki önemli noktalarve genlikleri

\begin{tabular}{cc}
\hline EKG dalgalar1 & Genlik $(\mathrm{mV})$ \\
\hline $\mathrm{P}$ & 0.25 \\
$\mathrm{Q}$ & $0.25 \times \mathrm{R}$ \\
$\mathrm{R}$ & 1.60 \\
$\mathrm{~T}$ & $0.1-05$ \\
\hline
\end{tabular}

Tablo 2. EKG sinyalindeki aralıklar ve süreleri

\begin{tabular}{cc}
\hline EKG aralıkları & Süre (saniye) \\
\hline P-R & $0.12-0.20$ \\
Q-T & $0.35-0.44$ \\
S-T & $0.05-0.15$ \\
Q-R-S & 0.09 \\
\hline
\end{tabular}


Gömülü sistemler teknolojisindeki gelişmelerle birlikte tıp konusunda son yıllarda önemli kazanımlar yapılmıştır. Böylece düşük maliyetli sağlık izleme sistemlerinin gerçekleştirilmesi mümkün hale gelmiştir.

Hastaların takibi için yapılan çalışmalar içinde, EKG sistemi ile sinyalin çeşitli elektronik filtrelerden geçirilerek algılanması ve işlenmesi gerçekleştirilmiştir. Gerçek zamanlı sinyal işleme ve izleme sisteminde iletken elektrotlar seçilerek performansları değerlendirilmiş ve EKG cihazı mikroişlemci tabanlı olarak tasarlanarak ara yüz programıyla ile haberleşebilecek yapıda geliştirilmiştir. Tasarlanan ara yüz programıyla kullanıcı tarafından ECG sinyalinin genliği ve sinyalin üzerindeki gürültü düzeyinin en aza indirilmesi kontrol edilebilir kılınmıştır.

$\mathrm{Bu}$ çalışmada hastanın kalp sinyalini ölçebilecek EKG tasarımı ve uygulamasıyla birlikte alınan kalp sinyallerinin Arduino'nun analog digital çeviricisi ile ara yüz programındaki grafik elkentisine gerçek zamanlı iletimi hedeflenmiştir.

\section{Yöntem}

EKG sistemi dört kısımdan meydana gelmektedir (Şekil 2). İlk kısımda EKG sinyalleri, vücut üzerine yerleştirilen elektrotlar sayesinde 16 kanallı girişlerden istenilen her hangi ikisinden alınır ve tek bir PQRST sinyaline dönüştürülür. Bu işlem sırasında EKG sinyalinin ilk yükseltilmesi yapılır. İkinci kısımda, oluşturulan bu sinyalin ikinci kat yükseltilmesi yapılır. Üçüncü kısımda ise çevresel manyetik alan, toprak, elektrotlardan gelen çeşitli gürültülerin süzülmesi için ayrı ayrı ve sırayla aktif alçak geçiren, aktif yüksek geçiren ve dar bantlı $50-60 \mathrm{~Hz}$ gürültüsünü önlemek için Notch filtresinden geçirilir [8].

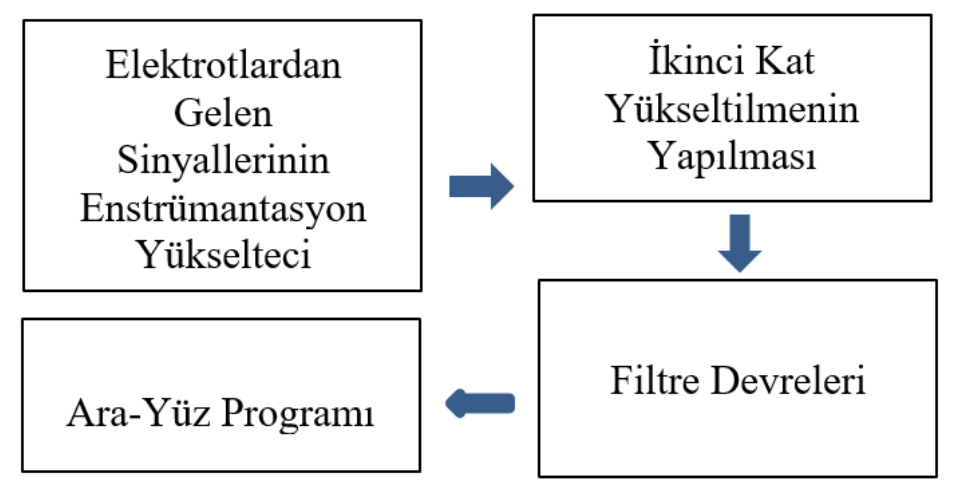

Şekil 2. EKG cihazı işlevsel blok diyagramı

Filtrelerden geçerek, üzerindeki gürültülerden yalıtılmış EKG sinyal ara yüz programına aktarılmak ve işlenebilmek için Arduino'nun analog dijital çevirici pinine gönderilir. Dördüncü ve kısımda ise ara yüz programı yardımıyla EKG sinyali ekrana aktarılarak, kullanıcı tarafindan değerlendirilmesi ve işlenmesi sağlanır. Sistemi oluşturan bütün bu evrelerin her birine, kullanıcı, ara yüz yardımıyla müdahale edebilir. Elektrot giriş kanallarının seçimini, EKG sinyalinin yükseltilme miktarını, alçak geçiren, yüksek geçiren ve notch filtresinin kesim frekansını, kullanıcı, ara yüzdeki çeşitli tab menülerini kullanarak belirleyebilir. 


\subsection{Elektronik tasarım}

Vücuda bağlanan elektrotlar ile alınan EKG sinyalleri maksimum $1 \mathrm{mV}$ genliğe sahip olduklarından dolayı bu sinyallerin işlenebilmesi genliklerinin yükseltilmesi gerekmektedir. Bu çalışmada, yüzey montaj (SMD) teknolojisiyle bir EKG elektronik kart tasarımı gerçekleştirilmiştir. Tasarlanan elektronik kartta, elektrotlardan alınan EKG sinyalleri INA128 enstrümantasyon yükselteciyle yükseltilmiştir. Tasarlanan aktif alçak geçiren filtre devresi (Şekil 3(a)) $50 \mathrm{~Hz}(\mathrm{Hertz}), 100 \mathrm{~Hz}$, $200 \mathrm{~Hz}, 500 \mathrm{~Hz}, 1 \mathrm{KHz}, 2 \mathrm{KHz}$ olmak üzere kullanıcı tarafindan belirlenebilen altı farklı kesim frekansına sahiptir. Aktif yüksek geçiren filtre devresi (Şekil 3(b)) ise $0.01 \mathrm{~Hz}, 0.05 \mathrm{~Hz}, 0.1 \mathrm{~Hz}$, $0.5 \mathrm{~Hz}, 1 \mathrm{~Hz}, 5 \mathrm{~Hz}$ olmak üzere kullanıcı tarafından belirlenebilen altı farklı kesim frekansına sahiptir. Tasarlanan bu iki aktif filtrenin dinamik olarak istenilen her an kesim frekansı ayarlanmak ile beraber alınan EKG sinyalinin üzerindeki çevresel gürültüler en üst düzeyde yalıtılması sağlanmıştır. Üzerinde bulunan Notch(çentik) filtre ile $50 \mathrm{~Hz}$ şebekeden gelecek gürültüler engellenmiştir.

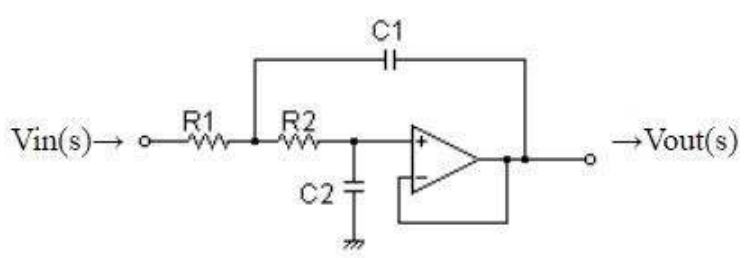

(a)

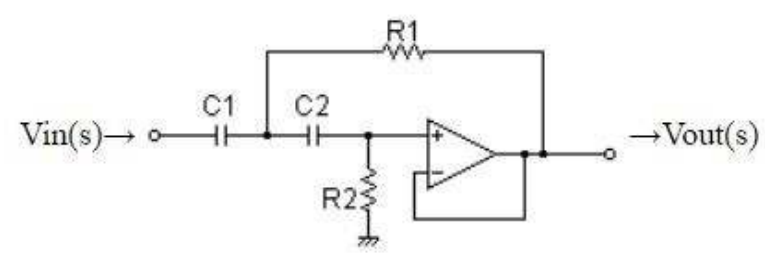

(b)

Şekil 3. EKG filtre devreleri: (a) Aktif alçak geçiren filter, (b) Aktif yüksek geçiren filter [6]

\subsection{Arayüz yazılımı}

Bu çalışmada Visual Studio 2017 bünyesinde ara yüz tasarım aracı bulunduran program kullanılmıştır. EKG elektronik kartının kontrolünün sağlandığı ara yüz programının sol üst köşesinde barındırdığı menü tabları, elektrotların giriş kanallarının tek tek kontrol edilmesini, sinyalin ikinci kat yükseltilme miktarını, aktif alçak geçiren, aktif yüksek geçiren filtrelerinin kesim frekanslarını gerçek zamanlı olarak belirlemeyi ve değiştirmeyi sağlamaktadır [9].

\section{Sonuçlar ve Tartışma}

Kalbin elektriksel aktivitesi sonucunda oluşan sinyalin vücut yüzeyinden algılanması için tek kullanımlık elektrotlar kullanılmıştır. Bu çalışmada 1mV'un altında alınan EKG sinyalleri işlenebilecek seviyelere yükseltmiş, EKG sinyalinin üzerindeki istenmeyen yüksek veya alçak frekanslar kullanılan filtreler yardımıyla ortadan kaldırılmış. Tasarım tamamen yüzey montaj (SMD) teknolojisiyle yapılmış olup Arduino eklentisi seklindedir. Arduino kartına konnektorlü şekilde tam oturmaktadır. EKG sinyalini elde ederken kullanılan malzemelerin toleransının geniş aralıkta olması gerek yükseltme miktarında sapmalar gerekse sinyalin gürültülü gelmesine neden olmuştur. İstenilen sonuçları elde etmek için toleransı dar malzemeler kullanılmıştır. Bu doğrultuda vücuttan alınan EKG sinyalleri iki kez yükseltilmiş, filtrelerden geçirilmiş ve ara yüz programı 
sayesinde analiz edilip işlenebilir hale getirilmişstir (Şekil 4).

Tasarlanan devrenin pozitif beslemesi Arduino kartı üzerinden alınmış olup eksi besleme doğrultucu entegresi kullanılarak elde edilmiştir. Ayrıca kart üzerinde kullanıcı tarafından ara yüz kullanılarak yapılan her bir seçme işlemi, kartın üzerinde gerekli yerlere yerleştirilmiş yüzey montaj ledler tarafından takip edilebilir kılınmıştır.

ECG sinyalinin elde edilmesindeki ilk aşama 74HC4051 entegrelerinin program ile sürülmesiyle elektrot kanallarının seçimiyle başlamaktadır. Seçilen kanallardan gelen sinyallerin INA128 enstrümantal yükselteç yardımıyla ilk kart yükseltilmesi gerçekleştirilmiştir. OPA377 kullanılarak oluşturulan yükseltici devresinin kazanç direnci, ara yüz programı kullanarak seçici entegre kontrolü ile kullanıcı tarafından belirlenir. EKG sinyali ikinci kez yükseltildikten sonra, yine kullanıcı tarafından kesim frekansları belirlenen filtrelerden geçerek Arduino üzerinden arayüz programıla ekrana yansitılmaktadir.

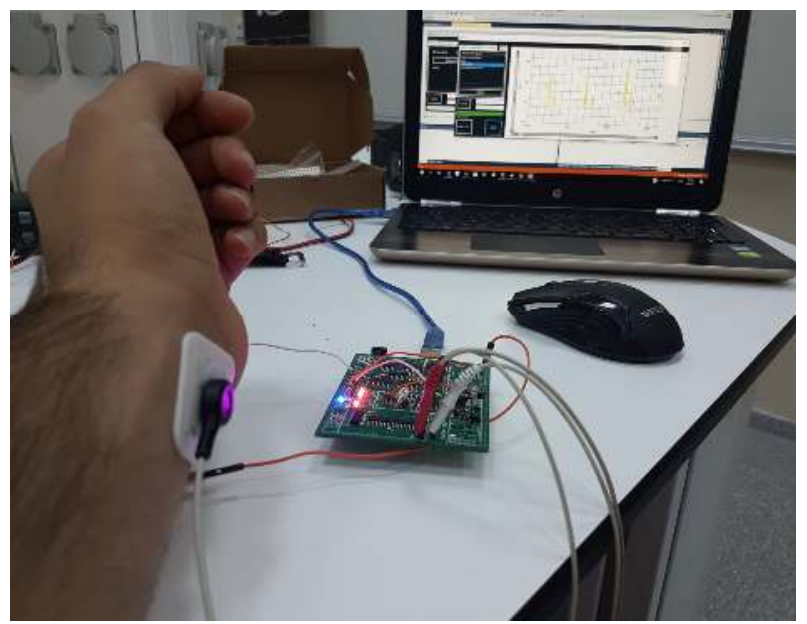

(a)

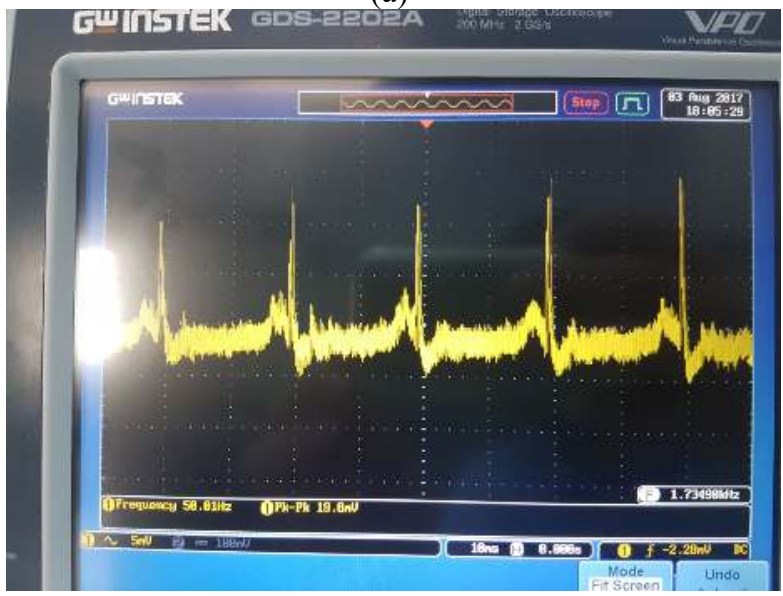

(c)

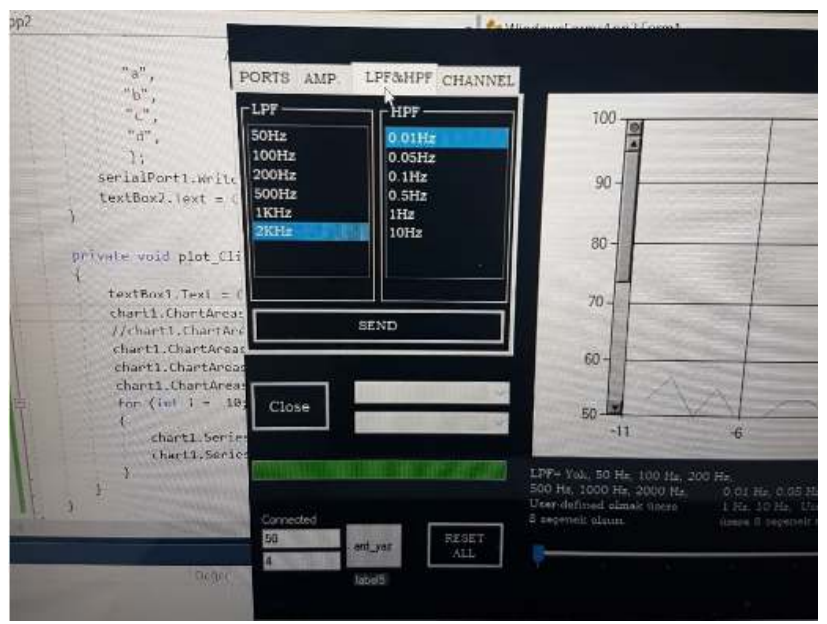

(b)

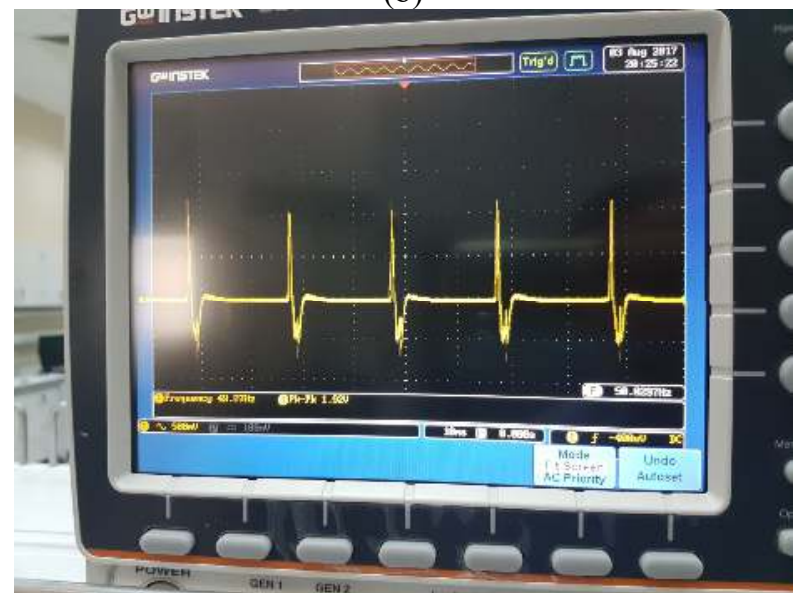

(d)

Şekil 4. Tasarlanan devre çalışırken: (a) Tasarlanan devre, (b) Yazılım ile filtre ayarları yapılırken, (c) Gürültülü EKG sinyali, (d) Gürültüsüz EKG sinyali 
Gerçekleştirilen bu sistem, gerçek zamanlı olarak kullanıcı tarafından 8 kanal elektrot girişinden her hangi ikisi seçilerek, sinyalin yükseltilme miktarı ayarlanarak ve filtre kesim frekansları belirlenerek gürültüden yalıtılmış sinyal elde edilmiş olunur. Ayrıca bu sistemle üniversite laboratuvarlarında aktif alçak ve yüksek filtre tasarımları, yükselteç tasarımları için Arduino eklentisi olarak kullanılabilir durumdadır. Kullanıcılar ara yüz programı sayesinde, istenilen kazanç miktarlarını ayarlayarak sinyal analizi yapabilir ve filtrelerin kesim frekanslarını değiştirerek giriş sinyallerinin bir filtre devresi karşısında nasıl değiş̧tiğini analiz edebilir.

\section{Teşekkür}

Çalışmaların yürütülmesi sırasında laboratuvar cihazlarının kullanımına yardım eden İzmir Katip Çelebi Üniversitesi Biyomedikal Mühendisliği Bölümü Araştırma Görevlilerinden Yüksek Mühendis Özlem KARABİBER CURA'ya teşekkür ederiz.

\section{Kaynaklar}

[1] Mettam GR, Adams LB. How to prepare an electronic version of your article. In: Jones BS, Smith RZ, editors. Introduction to the electronic age, New York: E-Publishing Inc; 1999, p. 281-304.

[2] İzgi A, Kırma C. Kardiyoloji kliniği. Kartal Koşuyolu Yüksek İhtisas Eğitim ve Araştırma Hastanesi, İstanbul, Türkiye.

[3] Yazgan E, Korürek M. Tıp elektroniği. İstanbul Teknik Üniversitesi Rektörlüğü Yayın Evi, İstanbul, Türkiye, 1996.

[4] Acartürk E. Pratik elektrokardiyografi. Kare Yayınları, Adana, Türkiye, 2001.

[5] Berbari EJ. Principles of electrocardiography. Editor: Bronzino JD. The biomedical engineering handbook, Second Edition, Boca Raton, FL, USA, CRC Press, 2003.

[6] Güler İ. Biyomedikal enstrümantasyon ders notları. Ankara, Türkiye, 2008; 239-255.

[7] Atar E. EKG bilgisi. Atlas Kitapçılık Yayınevi, İstanbul, Türkiye, 1993.

[8] Fard DJ. Sayısal nabız sayıcılı EKG yükselteci tasarım ve yapımı. Gazi Üniversitesi, Yüksek Lisans Tezi, Ankara, Türkiye, 1989.

[9] Ahlstrom M, Tompkins W. Digital filters for real-time ECG signal processing using microprocessors. IEEE Transactions on Biomedical Engineering, 1985; BME-32(9): 708-13. 